1897-03-27

\title{
Das Weib in seiner Geschlechtsindividualität
}

Frieda Freiin von Bülow

Follow this and additional works at: https://scholarsarchive.byu.edu/sophnf_essay

Part of the German Literature Commons

\section{BYU ScholarsArchive Citation}

Bülow, Frieda Freiin von, "Das Weib in seiner Geschlechtsindividualität" (1897). Essays. 1521.

https://scholarsarchive.byu.edu/sophnf_essay/1521

This Article is brought to you for free and open access by the Nonfiction at BYU ScholarsArchive. It has been accepted for inclusion in Essays by an authorized administrator of BYU ScholarsArchive. For more information, please contact scholarsarchive@byu.edu, ellen_amatangelo@byu.edu. 


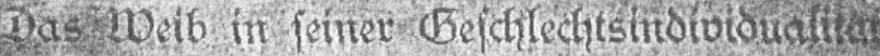

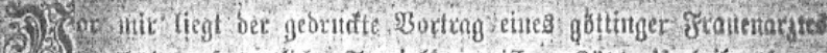

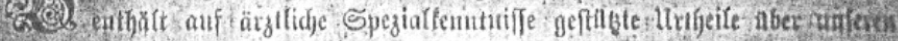

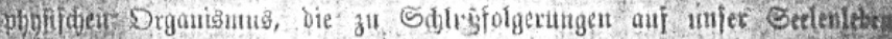

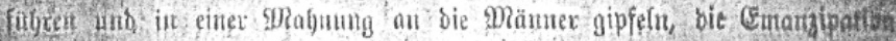
ber Jrau mit botler (5nergie zu befämpfer.

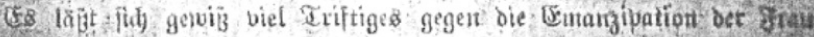

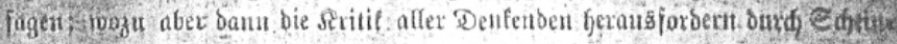

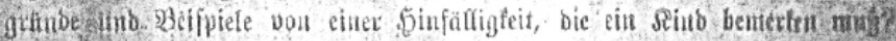

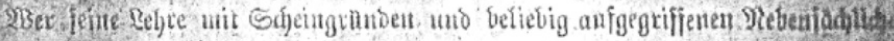

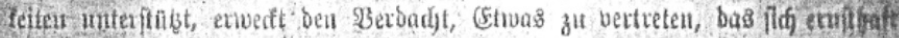

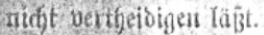

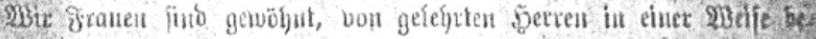

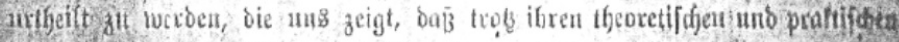

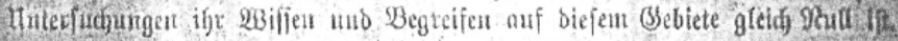

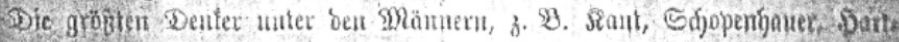

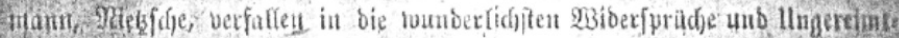

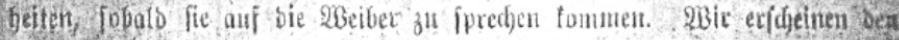

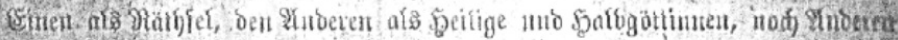
f

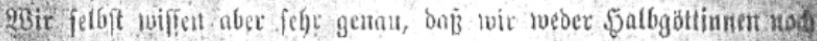

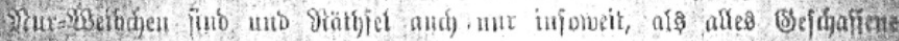

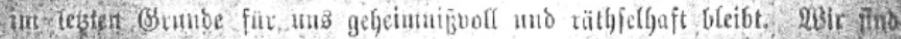

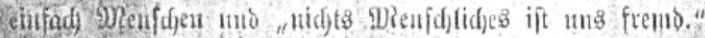

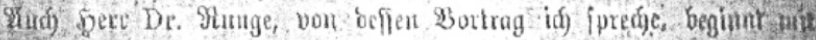

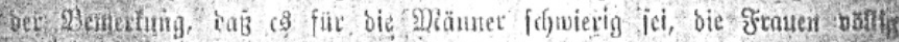

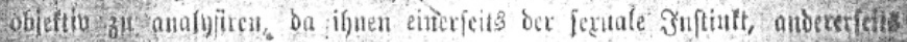

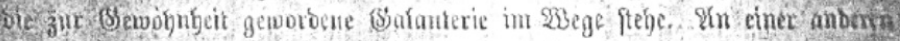

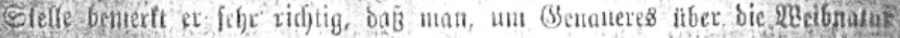

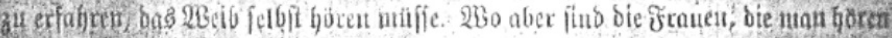

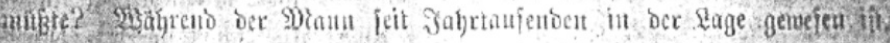

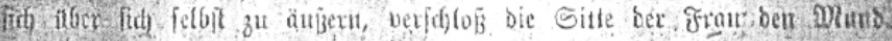

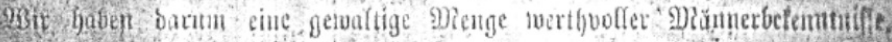

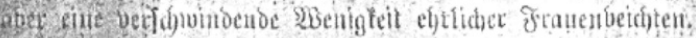

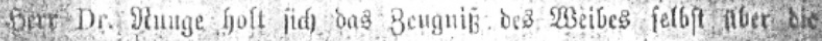

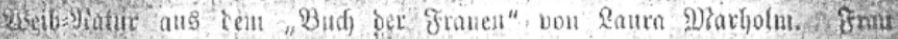

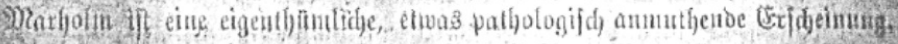

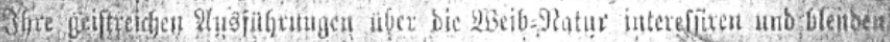

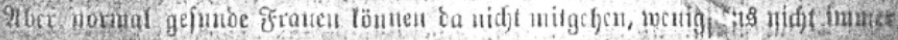




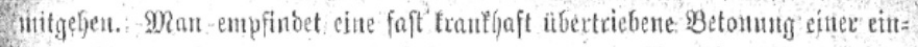

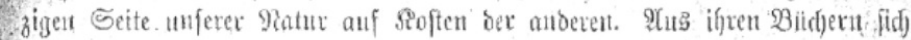

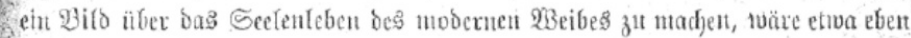

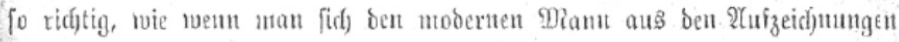

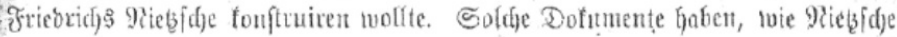

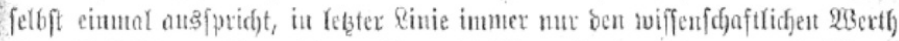

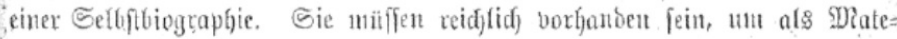

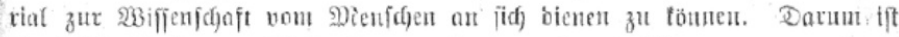

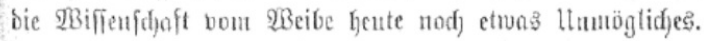

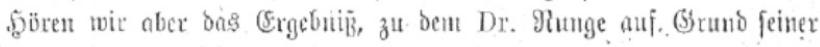
praftifdent nuto theoretiffon Studien getaugt ift.

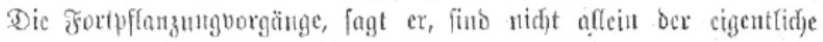

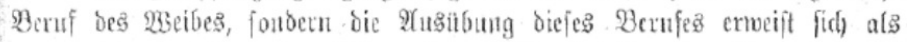

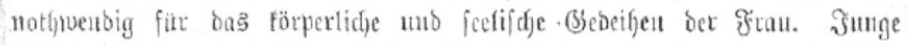

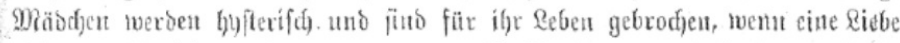

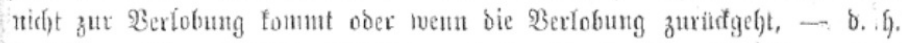

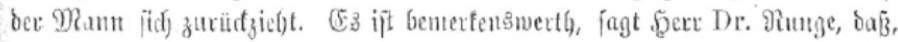

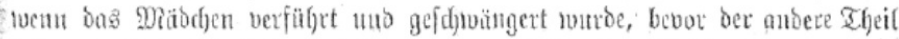

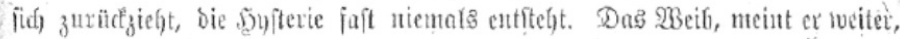

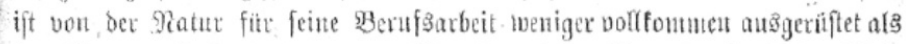

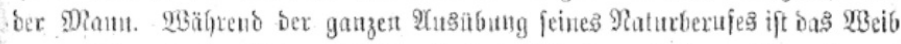
vegen feiner in Der Raturgcidjidjte einzig baftejeno ungüuftigen Säbrperbatart

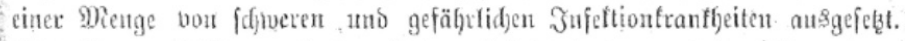

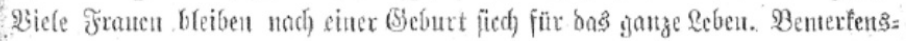
merti) endich ift, baj felbft böllig normal verfaufende (Beburten fid) mit fdyerent

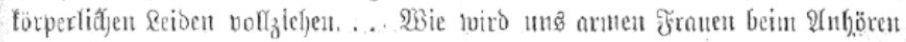

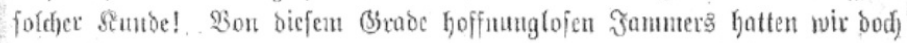

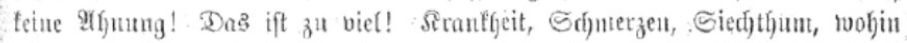

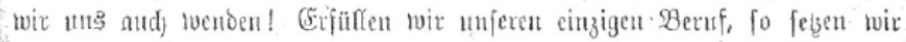

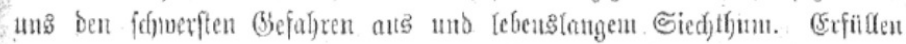
woir ifhe nidft, fo berfonmuen wir exft redft. Bemnod) fino wir zu nidjts

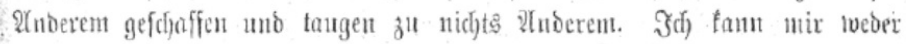

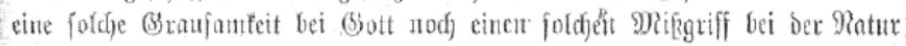

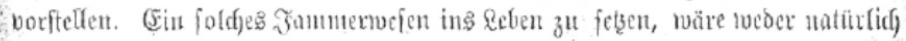
snod) göttlich, fondern fatanifd).

2Gie aber. Inffen firf bie (refd)einungen bes wirtlicfen Rebens nit biefer trofitrofen Rebre vom Weibe in Hebereinftimunng bringen?

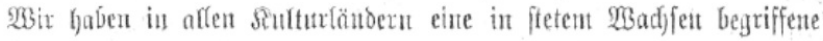

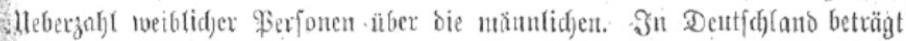

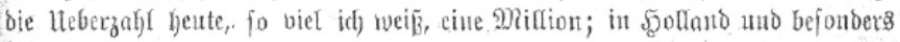




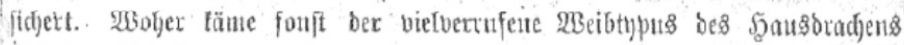
uni ber Sdjwiegermutter?

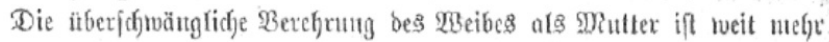

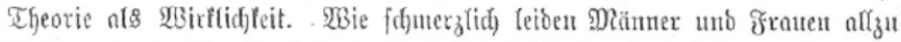

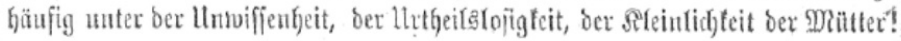

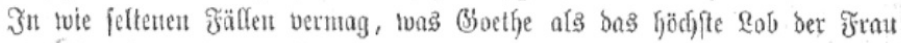

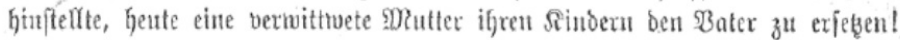

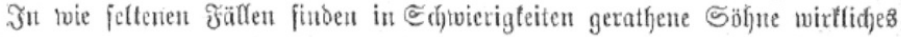
Berftänbuiß̧ bet ber Miutter! Die engherzig einfeitige Pautter uto bie teifente Sđ(f) bie Frant nidgt immer vor dent Ffud geiftiger Reere betuafgrt. (Sebt ifrent

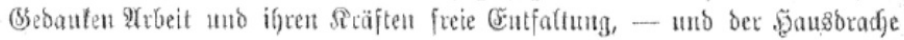

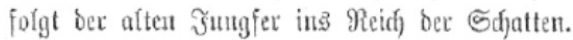

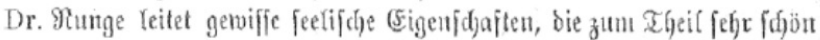

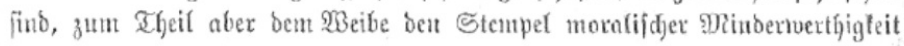

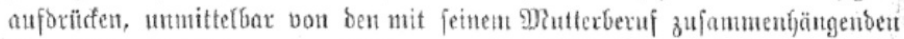
törperlidjen Buftänden ab. 2t(fein man Ğöre feine Beweisfür)rung: Die gé

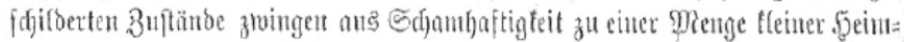

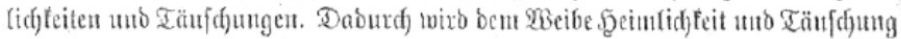

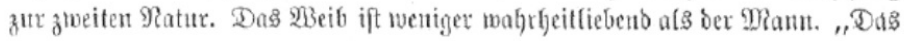

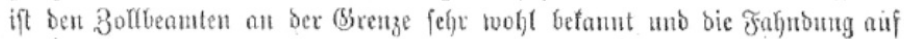
Contrebano wiro beim BBeibe meift genaner uno fäufig aud erforgreidjer

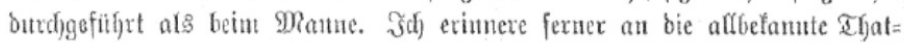

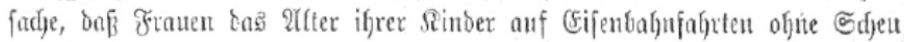

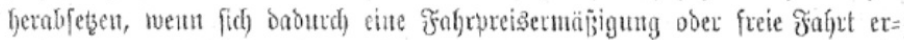

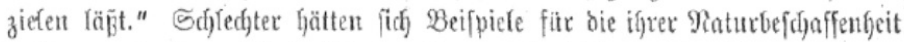

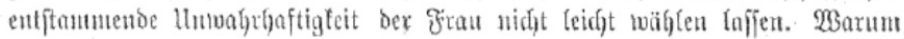

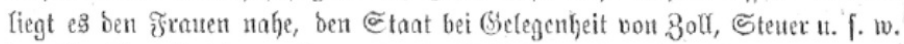

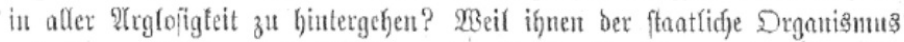
mit feinen Befezent uno Bfflic)ten niemals ein Begriff getwotoen iff. Sie

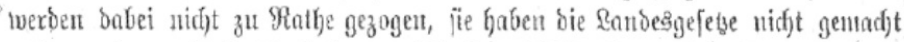

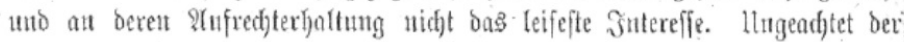
Ginfälligen Betweiafüfrung bleibt aber bie Thatfadje beftehen, baß̄ bie Fronten liftiger und unefreticjer finto afs bie Mänter. Stur ift bie Urfadje eine ganz

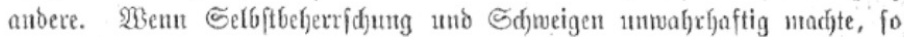

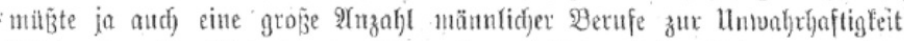

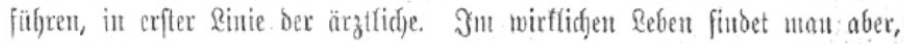

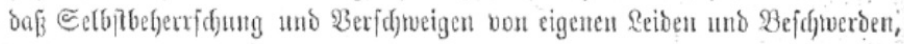

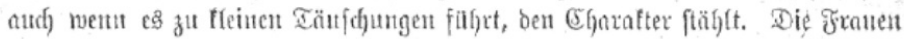

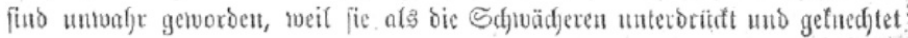




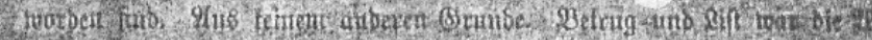

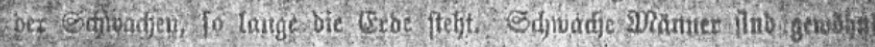

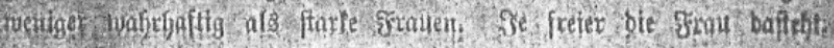

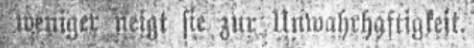

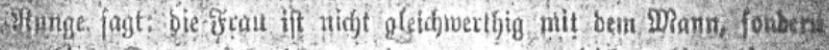

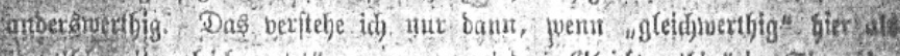

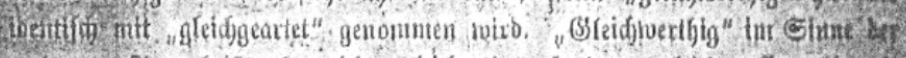

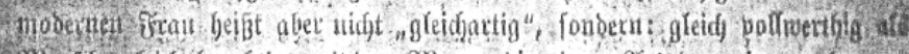

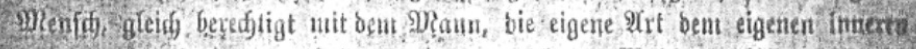

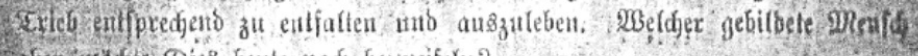
gber hitodite Diés Geute nod, bezweifeln?

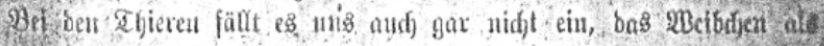

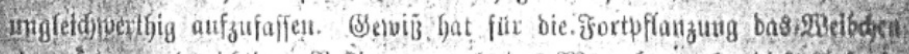

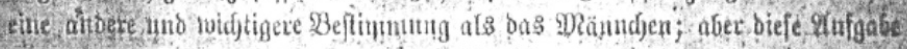

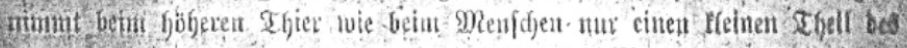

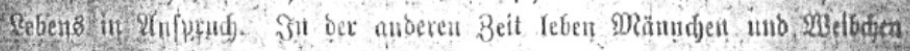

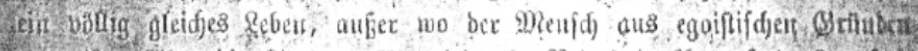

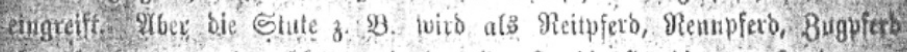

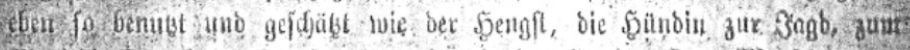

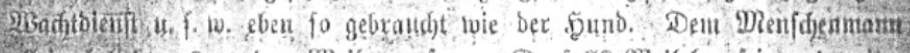

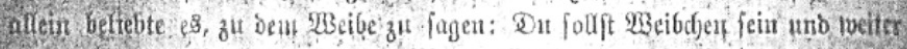

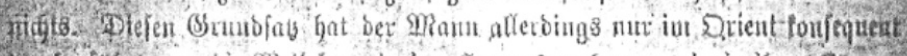

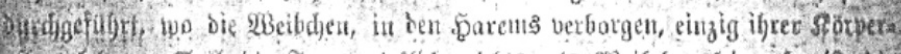

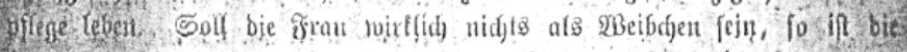

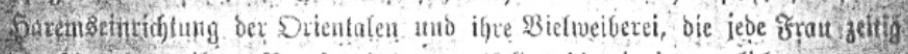

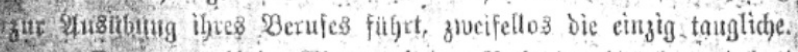

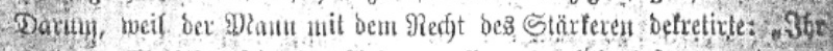

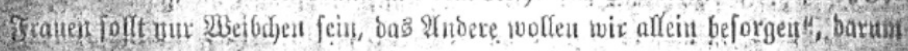

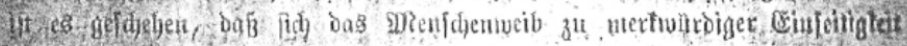

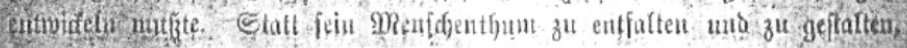

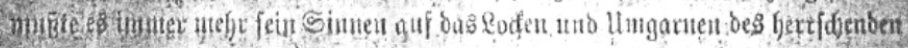

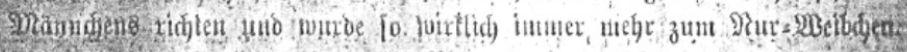

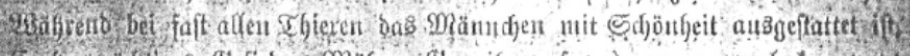

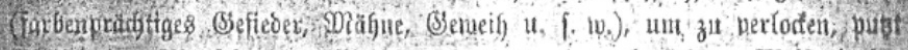

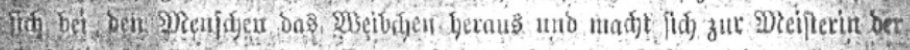

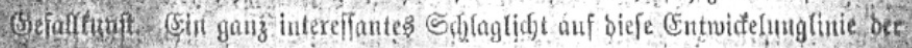

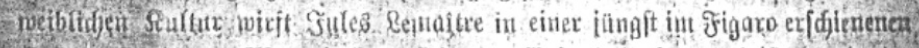

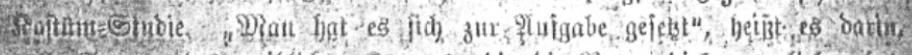

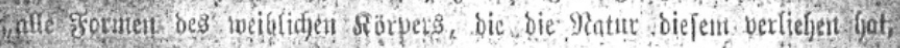

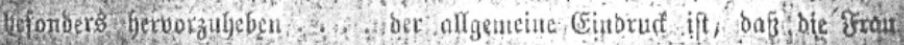


